\title{
XLVI. The photoelectric effect on thin films of platinum
}

\section{J. Robinson M.Sc. Ph.D.}

To cite this article: J. Robinson M.Sc. Ph.D. (1916) XLVI. The photoelectric effect on thin films of platinum , Philosophical Magazine Series 6, 32:190, 421-425, DOI: 10.1080/14786441608635587

To link to this article: http://dx.doi.org/10.1080/14786441608635587

曲 Published online: 08 Apr 2009.

Submit your article to this journal

Џll Article views: 2

Q View related articles $\square$

Citing articles: 7 View citing articles 5 
XLVI. The Photoelestric Effect on Thin Films of Platinum. By J. Robinson, M.Sc., Ph.D., Lecturer in Physics at East London College*.

THE photoelectric current from thin films of platinum does not increase uniformly with the thickness, but varies $\dagger$ as shown in Curve A, fig. 2. This applies whether the incident or emergent effect is considered ; $i$. e., whether the light falls on the platinum film belore or after passing through the quartz plate on which the film is deposited. For thicknesses below about $10^{-7} \mathrm{~cm}$., i. e. from where the current is a maximum, the emergent eflect is larger than the incirdent effect both as regards current and velocities $t$. An explanation of the difference in magnitude of the incident and emergent currents was offered by Partzsch and Hallwachs §, who showed that in the emergent case more light is absorbed than in the incident case. This wonld offer a full enough explanation if the magnitude of the effects were exactly the same, but it would not explain the difference in velocities. Hence doubt was cast on the result that the velocities do differ. It has since been shown by Stublmann $\|$, who used a method similar to the author's, that the emergent velocity is larger than the incident velocity.

Partzsch and Hallwachs' result, that more light is absorbed in the emergent case, shows the necessity for further work to find :-in the first place, what the asymmetry of the currents is when unit quantity of light is absorbed in each case, and in the second place, whether for very thin films the absorption of light varies with the thickness in a way similar to that of the current.

In the experiments to be described, an attempt was made to get some information on these problems. It was considered advisable to make the measurements of the absorption of light on the same films on which the photoelectric measurements were made.

A DEK is a nearly closed metallic cylinder standing on a base D E. 'There is a small inlet of light at $B$. The

* Communicated by Prof. C. H. Leen, F.R.S.

+ Robinson, Phil. Mag. xxr. p. 122 (1913); Werner, Ark. Mat. Ast. Fys. viii. no. 37, p. I (1913) ; Stuhlmann \& Compton, Phys. Rev. ser. 2, ii. pp. $189 \& 327$ (1913).

I hobinson, loc. cit.

\$ Partzsch \& Hallwachs, Ann. des Phys. xli. p. 247 (1913).

if Phys. Rev. iv. p. 195 (1914). 
ressel thus acts nearly as a black body, and very little light which enters at $B$ can escape again. Thus it is all absorbed somewhere in the vessel. $C$ is a platinum film on quart: arranged so that a parallel beam of light entering at B falls on it. Let $I_{0}$ be the intensity of light entering at $B$, and

Fig. 1.

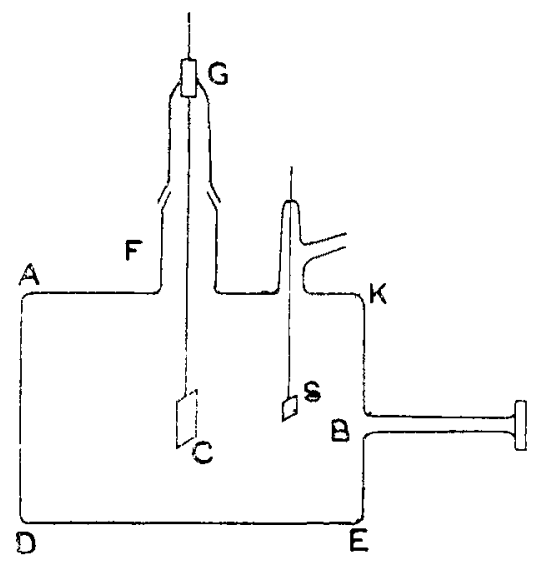

hence falling on $\mathrm{C}$. A certain proportion of this, $a \mathrm{I}_{0}$, is absorbed by the film, $\beta \mathrm{I}_{0}$ is reflected, and $\gamma \mathrm{I}_{0}$ is transmitted, where $\alpha+\beta+\gamma=1$. The amount of light $(\beta+\gamma) \mathrm{I}_{0}$ is absorbed by the vessel. The amount of light $\alpha \mathrm{I}_{0}$ is that which produces the photo current in the film. We need to find $i_{1}$, the photo current from the film, and $\alpha \mathrm{I}_{0}$, the light absorbed by the film. The photo current $i_{1}$ can be measured by charging the walls of the vessel to a potential to drive the electrons away from the film.

Suppose that $\dot{\mathrm{I}}_{0}$ is kept constant, and with a mercuryvapour lamp it can be kept practically constant. Then $\alpha=1-(\beta+\gamma)$, where $(\beta+\gamma) \mathrm{I}_{0}$ is the amount of light absorbed by the walls of the vessel. These walls remain constant throughout a series of experiments, and if the photo current from the walls is measured by applying a potential to drive electrons to the film, this current is proportional to the amount of light absorbed by the walls, and hence to $(\beta+\gamma)$. Thus $\alpha$ can be obtained in terms of the photo current of the walls of the vessel. a itself cannot he absolutely determined in each case unless some moans is found for measuring the intensity of the light, or unless another set of experiments is made, so that $I_{0}$ can be eliminated from the equations. 
This was at first attempted by arranging a screen at $S$ of the same material as the walls of the vessel, so that the relative amounts of light falling on the film and the vessel could be altered. This was abandoned, as it was quite sufficient for the present purpose to know how a varies with the thickness.

A quartz tube was cemented to the side tube to let ultraviolet light into the ressel. Another side piece, F, had a ground joint for the purpose of rotating the film C. The rod carrying the quartz plate for the nilm was insulated at $G$ by an amber plug. The contact between the film and the rod was mide as in a former paper, by getting a thick deposit of platinum at an edge of the quartz-plate, laying tinfoil over this so as to allow part of the thick platinum film to be uncovered, and clamping this prepared edge of the quartz to the rod. The films to be tested were deposited over the whole of one side of the quartz plate, and only the centre of the plate was exposed to the light. The plate was of dimensions $10 \mathrm{~mm} . \times 8 \mathrm{~mm} . \times 1 \mathrm{~mm}$.

The inside of the ressel was coated with soot from burning camphor in one series of experiments, and in another series consisted of zinc. 'The platinum film was joined to a pair of quadrants of a Dolezalek electrometer whose sensitiveness was 2000 divisions per volt, when the needle was charged to 100 volts. The current from the film was measured by charging the walls of the vessel to a high positive potential, and that from the walls by charging them to a high negative potential, so that the maximum effects were obtained in each case.

The following results were obtained :-

Table I.

\begin{tabular}{|c|c|c|}
$\begin{array}{c}\text { Thickness of } \\
\text { film. }\end{array}$ & $\begin{array}{c}\text { Current frum } \\
\text { film. }\end{array}$ & $\begin{array}{c}\text { Current from the walls } \\
\text { of the vessel. }\end{array}$ \\
\hline 50 seconds. & 8 & 51 \\
80, & 22 & 465 \\
130, & 235 & 41 \\
240, & 150 & 16 \\
\hline
\end{tabular}

The thickness of the film was measured in terms of the length of time to deposit it. The quartz plate was taken out of the vessel in each case and placed in a discharge-tube with a platinum cathode to have the film formed or thickened. 
These results are shown graphically in fig. 2.

Fig. 2.

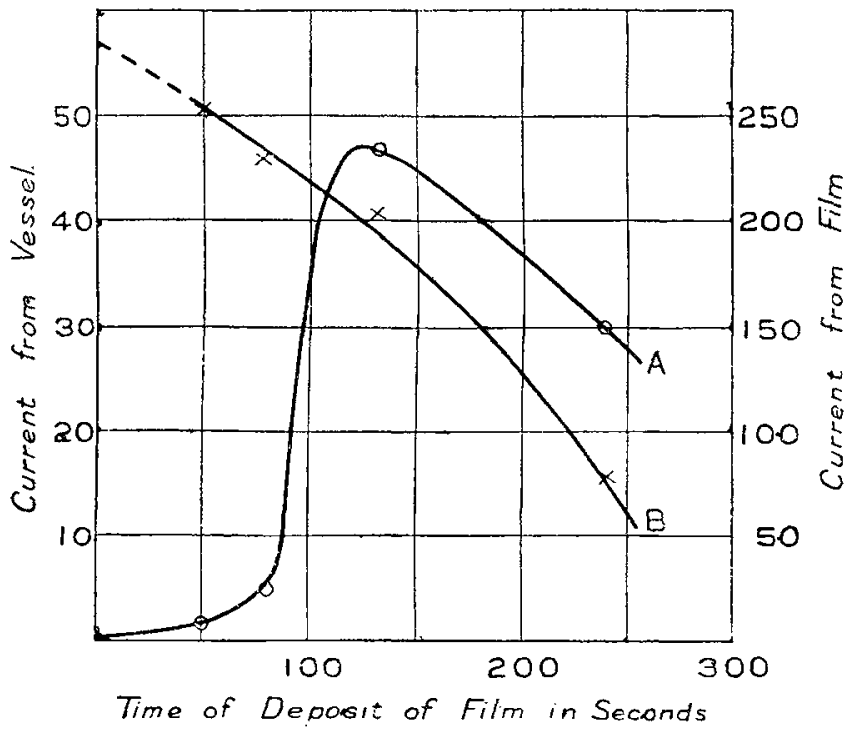

Curve A.-Photo current for varions thichnesses of film.

Curve B.-Photo current from the walls of the vessel.

It is seen that the current from the film varies with the thickness in the way already demonstrated ${ }^{*} ; i$. e., it increases graduallv with the thickness at first, then it suddenly increases rapidly, after which it falls again. The current from the walls of the vessel diminishes uniformly, and it is proportional to the light absorbed by the vessel. Hence $(\beta+\gamma) I_{0}$ diminishes uniformly as the thickness of film increases, and hence $\alpha \mathrm{I}_{0}$ the light absorbed by the film increases uniformly with the thickness. Producing the curve for the current from the vessel backwards, we find the current that would have been obtained had no light been absorbed by the film. This value is 57 in the units employed, and this gives an arbitrary measure of the intensity of light $\mathrm{I}_{0}$ on entering the vessel. Curve A (fig. 3) shows how the light absorbed by the film varies with the thickness. It was found by subtracting the ordinates of the curve $B$ (fig. 2) from 57.

It is at ance obvious that the large photo current at the thickness $10^{-7} \mathrm{~cm}$. is not produced by an abnormal absorption of light.

In Table II. values for the current from the film and light

* Robinson, loc. sit. 
absorbed by the film as obtained from the curve A (fig. 2) and curve A (fig. 3) are given for various thicknesses, as. also are the photo currents for unit absorption of light.

Fig. 3.

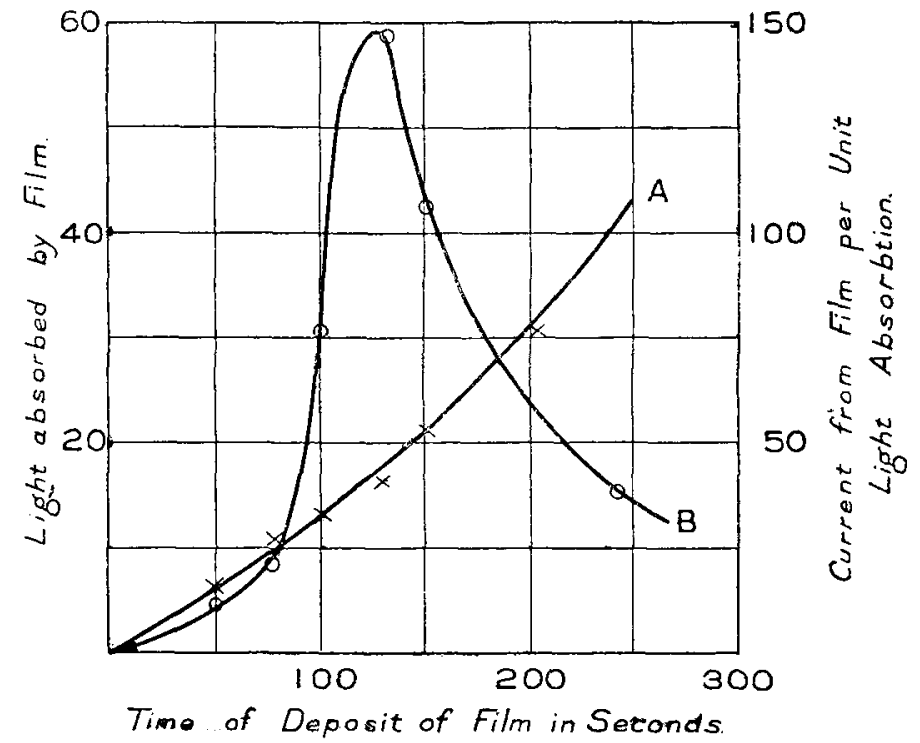

Curve A. - Intensity of light absorbed by the film.

Curve B.-Photo current for unit intensity of light absorbed.

TABLE II.

\begin{tabular}{|c|c|c|c|}
\hline $\begin{array}{c}\text { Thickness of film } \\
\text { in seconds. }\end{array}$ & $\begin{array}{c}\text { Current from } \\
\text { film. }\end{array}$ & $\begin{array}{c}\text { Light } \\
\text { absorbed. }\end{array}$ & $\begin{array}{c}\text { Current per unit } \\
\text { light absorbed. }\end{array}$ \\
\hline 50 & 8 & 6 & 13.3 \\
80 & 22 & 10.5 & 21 \\
100 & 100 & 13 & 77 \\
130 & 235 & 16 & 147 \\
150 & 220 & 21 & 105 \\
200 & 178 & 31 & 58 \\
240 & 150 & 41 & 37 \\
\hline
\end{tabular}

In curve B (fig.3) are plotted the photo currents per unit absorption of light against the thickness of film, and the maximum value of the current appears still more pronounced. The photoelectric sensitiveness of platinum is thus very large for films of the order of $10^{-7} \mathrm{~cm}$.

June 19, 1916. 